\title{
Methotrexate upregulates circadian transcriptional factors PAR bZIP to induce apoptosis on rheumatoid arthritis synovial fibroblasts
}

Kohjin Suzuki ${ }^{1}$, Kohsuke Yoshida ${ }^{1}$, Takeshi Ueha², Kenta Kaneshiro ${ }^{1}$, Ayako Nakai ${ }^{1}$, Naonori Hashimoto ${ }^{1}$, Koto Uchida', Teppei Hashimoto ${ }^{3}$, Yoshiko Kawasaki ${ }^{3}$, Nao Shibanuma ${ }^{4}$, Natsuko Nakagawa ${ }^{5}$, Yoshitada Sakai ${ }^{2}$ and Akira Hashiramoto ${ }^{1 *}$

\begin{abstract}
Background: Effects of methotrexate (MTX) on the proliferation of rheumatoid arthritis (RA) synovial fibroblasts are incompletely understood. We explored actions of MTX in view of circadian transcriptions of synovial fibroblasts.

Methods: Under treatment with MTX, expression of core circadian clock genes, circadian transcriptional factor proline and acidic amino acid-rich basic leucine zipper (PAR bZIP), and proapoptotic molecule Bcl-2 interacting killer (Bik) was examined by real-time polymerase chain reaction. Protein expression of circadian clock gene PERIOD2 (PER2) and CYTOCHROME C was also examined by western blotting and ELISA. Promoter activities of Per2 and Bik were measured by Luciferase assay. Expression of PER2, BIK, and CYTOCHROME $C$ and morphological changes of the nucleus were observed by fluorescent immunostaining. Synovial fibroblasts were transfected with Per2/Bik small interfering RNA, and successively treated with MTX to determine cell viabilities. Finally, synovial fibroblasts were treated with MTX according to the oscillation of Per2/Bik expression.

Results: MTX (10 nM) significantly decreased cell viabilities, but increased messenger RNA expression of Per2, Bik, and PAR ZIP including D site of the albumin promoter binding protein (Dbp), hepatic leukemia factor (HIf), and thyrotroph embryonic factor (Tef). MTX also increased protein expression of PER2 and CYTOCHROME C, and promoter activities of Per2 and Bik via D-box. Under fluorescent observations, expression of PER2, BIK, and CYTOCHROME C was increased in apoptotic cells. Cytotoxicity of MTX was attenuated by silencing of Per2 and/or Bik, and revealed that MTX was significantly effective in situations where Per2/Bik expression was high.
\end{abstract}

Conclusions: We present here novel unique action of MTX on synovial fibroblasts that upregulates PAR bZIP to transcribe Per2 and Bik, resulting in apoptosis induction. MTX is important in modulating circadian environments to understand a new aspect of pathogenesis of RA.

Keywords: Rheumatoid arthritis, Synovial fibroblasts, Methotrexate, Proline and acidic amino acid-rich basic leucine zipper, Period2, Bcl-2 interacting killer

\footnotetext{
* Correspondence: hash@med.kobe-u.ac.jp

1 Department of Biophysics, Kobe University Graduate School of Health

Sciences, Tomogaoka 7-10-2, Suma-ku, Kobe 654-0142, Japan

Full list of author information is available at the end of the article
} 


\section{Background}

Methotrexate (MTX) is a folic acid antagonist widely used as anchor drug in treating various cancers $[1,2]$, as well as rheumatoid arthritis (RA) [3]. For cancer cells, MTX competitively inhibits dihydrofolate reductase (DHFR) to block purine and pyrimidine biosynthesis, and thus it inhibits DNA replication and cell proliferation. For RA, low-dose MTX shows anti-inflammatory effects by inducing extracellular adenosine, which binds to adenosine receptors [4]. Moreover, it has been reported that MTX induced apoptosis in synovial fibroblasts in both in-vivo and in-vitro experiments [5]. Although MTX induced apoptosis in synovial fibroblast within 24-48 $\mathrm{h}[6,7]$, the precise mechanism of how MTX expresses antiproliferative effects on synovial fibroblasts remains incompletely understood [8].

RA is a chronic arthritis characterized by 'tumor-like' synovial cell growth [9]. Another remarkable feature of RA is the circadian variation of disease-related symptoms, such as morning stiffness, increased production of proinflammatory cytokines at night time, and peaked secretion of immunoglobulin (Ig) A/IgM types of rheumatoid factor in the morning [10-15]. Since these rheumatic symptoms possess a daily rhythm, we have previously shown that the action of the biological clock was significantly disturbed in the mouse model of collagen antibody-induced arthritis [16] and that tumor necrosis factor (TNF)- $\alpha$ significantly disturbed the oscillation of biological clocks of synovial fibroblasts [17]. Fibroblasts usually demonstrate daily rhythms of circadian clock, while Haas et al. [18] pointed out that the expression rhythm of clock genes disappears in RA synovial fibroblasts presumably due to prolonged inflammation.

The circadian rhythm in human cells is mainly regulated by the core clock genes, including circadian locomotor output cycles kaput (Clock), brain and muscle Rant-like protein-1 (Bmal1), period (Per), and cryptochrome (Cry) [19-22]. The circadian transcriptional factor proline and acidic amino acid-rich basic leucine zipper (PAR bZIP) includes the $\mathrm{D}$ site of the albumin promoter binding protein $(D b p)$, hepatic leukemia factor $(H l f)$, and thyrotroph embryonic factor (Tef). PAR bZIP regulates gene expression by binding to a consensus sequence of D-box ( $5^{\prime}$ TTAXGTAA-3'; $\mathrm{X}=\mathrm{T}$ or $\mathrm{C}$ ) on the promoter region $[23-\overline{25}]$. It has been reported that PAR bZIP can regulate the transcription of Per 2 gene by binding two D-box sequences existing on its promoter (D-box 1, $5^{\prime}$-TTATG TAA-3', -372 to -365; and D-box 2, 5' -TTACGTAA-3', $-\overline{47}$ to -40 ) [24]. In contrast, E4-binding protein 4 (E4bp4) also binds to the D-box to suppress the transcription of Per2 [26-28] (see Additional file 1).

It is noted that Bcl-2 interacting killer (Bik) possesses Dbox (5'-TTAAGTCA-3', -285 to -277 ) on its promoter region [28], resembling the arrangement of Per2 genes. Bik, a member of the BH3-only subfamily, acts as an important signaling molecule upstream of the Bcl-2 and Bax subfamily [29]. The BCL-2 family has been known to be central players in regulating physiological activities of mitochondria, with Bcl-2, Bcl-xL, and $\mathrm{Mcl}-1$ suppressing mitochondria-related apoptosis, whereas Bax and Bak induce it. Among these, Bik directly binds to these family proteins to induce apoptosis [29, 30].

In this study, we explored novel pharmacological effects of MTX on circadian clock genes and apoptosis induction in RA synovial fibroblasts.

\section{Methods}

\section{Synovial fibroblast culture}

Synovial tissues were obtained from RA patients (eight females and two males; aged $59.3 \pm 3.4$ years) during joint surgery. Eight of 10 patients took methotrexate and their average dosage was $7.4 \pm 1.4 \mathrm{mg} /$ week (Table 1) (see Additional file 2). This study has been approved by the ethics committee of Kobe University Graduate School of Health Sciences (\#579-1) and Kobe Kaisei Hospital (\#0072), in accordance with the Declaration of Helsinki. Written informed consent was obtained from each patient before study enrolment. Tissues were minced and treated with $2 \mathrm{mg} / \mathrm{ml}$ collagenase (Wako, Tokyo, Japan) in serumfree Dulbecco's modified Eagle's medium (DMEM; Nissui, Tokyo, Japan) at $37{ }^{\circ} \mathrm{C}$ for $1 \mathrm{~h}$. Primary cultured synovial cell lines were established and maintained in DMEM including 10\% heat-inactivated fetal bovine serum (FBS; Thermo, Waltham, MA, USA), 1\% penicillin-streptomycin (100 U/ml; Life Technologies, Carlsbad, CA, USA),

Table 1 Characterization of patients

\begin{tabular}{ll}
\hline Characteristic & Value \\
\hline Patients $(n)$ & 10 \\
Age (years) & $59.3 \pm 3.4$ \\
Sex (female/male) & $8 / 2$ \\
Disease duration (years) & $22.7 \pm 3.2$ \\
C-reactive protein (mg/dl) & $1.2 \pm 0.4$ \\
DAS28-ESR & $2.6 \pm 0.4$ \\
Methotrexate (mg/week) & $7.4 \pm 1.4$ \\
Methylprednisolone (mg) & $3.7 \pm 0.9$ \\
Other DMARDs & \\
Adalimumab & $2 / 10$ \\
Tocilizumab & $2 / 10$ \\
Tacrolimus & $2 / 10(2,1.5 \mathrm{mg})$ \\
Etanercept & $2 / 10$ \\
Infliximab & $1 / 10$ \\
None & $2 / 10$ \\
\hline
\end{tabular}


and 1\% L-glutamine ( $2 \mathrm{mM}$; Life Technologies), in a humidified incubator at $37{ }^{\circ} \mathrm{C}$ in the presence of $5 \% \mathrm{CO}_{2}$. Harvested cells were continuously cultured to obtain synovial fibroblasts, and cells of passages 3-6 were used in the entire experiments.

\section{Synchronization of synovial fibroblasts by serum shock}

Synovial fibroblasts were incubated in 50\% horse serum and incubated for $2 \mathrm{~h}$ to synchronize the expression of clock genes [17, 31].

\section{Cell viability assay}

Synovial fibroblasts $\left(3.0 \times 10^{3}\right.$ cells $)$ were cultured in serum-free DMEM with or without MTX $(1,10$, and 100 nM, $1 \mu$; Sigma Aldrich, St. Louis, MO, USA). After incubating for 24-72 h, cell viabilities were measured as the 450-nm absorbance of reduced WST-8 (2-(2-methoxy-4-nitrophenyl)-3-(4-nitriphenyl)-5-(2, 4-disulphonyl)$2 \mathrm{H}$-tetrazolium, monosodium salt) using the Cell Counting Kit-8 (Dojindo, Kumamoto, Japan). The values were represented relative to MTX-untreated cells (control).

\section{Real-time polymerase chain reaction}

Synovial fibroblasts $\left(8.0 \times 10^{4}\right.$ cells $)$ were cultured in serum-free DMEM with or without MTX (10, $100 \mathrm{nM})$ for 24-32 h. After incubation, total RNA was extracted using the RNeasy Mini Kit (QIAGEN, Hilden, Germany). Then, reverse transcription was performed with the ReverTra Ace ${ }^{\circ}$ qPCR RT Kit (Toyobo, Osaka, Japan) and analyzed on the StepOnePlus ${ }^{\text {mix }}$ Real-Time PCR System (Applied Biosystems, Foster City, CA, USA). The TaqMan probes used were: Hs00154147_m1 for Bmal1, Hs00231857_m1 for Clock, Hs00256143_m1 for Per2, Hs00172734_m1 for Cry1, Hs00609747_m1 for Dbp, Hs00171406_m1 for Hlf, Hs01115720_m1 for Tef, Hs00993282_m1 for E4bp4, Hs00154189_m1 for Bik, and Hs00427621_m1 for TATA box binding protein $(T b p)$. Expression levels were normalized to $T b p$.

\section{Western blotting}

Synovial fibroblasts $\left(5.0 \times 10^{5}\right.$ cells $)$ were cultured in serumfree DMEM with or without MTX $(10,100 \mathrm{nM})$ for 24-48 $\mathrm{h}$, and lysed with RIPA buffer (Wako) to obtain cytoplasmic proteins. Samples were subjected to sodium dodecyl sulfate polyacrylamide gel electrophoresis (SDS-PAGE), transferred to polyvinylidene difluoride (PVDF) membrane (Millipore, Bedford, MA, USA), probed with antibodies, and developed by ImmunoStar ${ }^{\circ}$ LD (Wako). Antibodies (Abs) used were: anti-PER2 Ab (sc-101,105; Santa Cruz, Dallas, TX, USA), anti-CYTOCHROME C Ab (ab13575; Abcam, Cambridge, UK), anti-BIK Ab (NB100-56109; Novus, Littleton, CO, USA), anti-Actin Ab (sc-1616; Santa Cruz), anti-mouse IgG Ab (NA9310; GE Healthcare, Chicago, IL, USA), and antirabbit IgG Ab (NA9340; GE Healthcare).

\section{ELISA for PER2 and CYTOCHROME C}

Synovial fibroblasts $\left(3.0 \times 10^{3}\right.$ cells $)$ were cultured in serum-free DMEM with or without MTX $(10,100 \mathrm{nM})$ for 32-48 h, and protein expression of PER2 and CYTOCHROME $\mathrm{C}$ was measured by the In Cell ELISA test kit (3440-02; Thermo). Antibodies were as already described.

\section{Luciferase reporter gene construction}

Genomic DNA was obtained from RA synovial fibroblasts and amplified by PCR to generate the luciferase reporters. The primer pairs used for amplifying human Bik promoter containing D-box $(-780$ to +176$)$ were $5^{\prime}$ TGGCCTAACTGGCCGTAAACAAGCTTTGCCGTGC -3 ' (forward) and 5' -CGCCGAGGCCAGATCATGCTGG CAGCGTCTGTA-3' (reverse). The primer pairs used for amplifying human $B i k$ promoter without D-box $(-260$ to +323$)$ were $5^{\prime}$-TGGCCTAACTGGCCGCCTCTTG GAGCCTCGGTT-3' (forward) and 5'-CGCCGAGGC CAGATCTTGCTGGAGCGGTAAAACC-3' (reverse). The KpnI recognition sequence was added to the $5^{\prime}$ ends of forward primers and the BglII recognition sequence was added to the $5^{\prime}$ ends of reverse primers. The PCR products were cloned into the KpnI and BglII site of the pGL4.10 (luc2) vector (Promega, Madison, WI, USA) using In-Fusion ${ }^{\bullet}$ HD Cloning Plus (Takara, Shiga, Japan). The luciferase reporters containing Per2 promoters were generated with reference to Yoshida et al. [17]. D-box motifs of Per2 promoter were mutated from 5' -TTATGTAA-3' to 5'-CGCCAGGC-3' (-372 to $-365)$ and from $5^{\prime}$-TTACGTAA-3' to $5^{\prime}$-CAGCGTAA$3^{\prime}$ ( -47 to -40$)$ (see Additional file 3).

\section{Transient transfection and luciferase reporter assay}

Synovial fibroblasts $\left(4 \times 10^{4}\right.$ cells $)$ were transfected with $500 \mathrm{ng}$ of the pGL4.10 (luc2) vector containing various Per2 and Bik promoters using Lipofectamine 3000 Transfection Reagent (Thermo). As an internal control, $35 \mathrm{ng}$ of pRL-TK (Promega) containing the herpes simplex virus thymidine kinase promoter driving Renilla luciferase was cotransfected. After $24 \mathrm{~h}$ of incubation for transfection, cells were treated with 10 and $100 \mathrm{nM}$ MTX for $24 \mathrm{~h}$, and analyzed for luciferase activity using the Dual-Luciferase Reporter Assay (Promega). Activities of both firefly and Renilla luciferases were measured, and the activity of firefly luciferase was normalized by Renilla luciferase. The values were shown as relative variations to MTX-untreated cells.

\section{Fluorescent immunostaining}

Synovial fibroblasts $\left(6.0 \times 10^{3}\right.$ cells $)$ were cultured in serumfree DMEM with or without MTX $(10 \mathrm{nM})$ for $24 \mathrm{~h}$. Then, cells were fixed with $4 \%$ formaldehyde, stained with antiPER2 Ab, anti-BIK Ab, anti-CYTOCHROME C Ab, antimouse IgG $(\mathrm{H}+\mathrm{L}), \mathrm{F}\left(\mathrm{ab}^{\prime}\right)_{2}$ Fragment (Alexa Fluor 594 
Conjugate) (\#8890; Cell Signaling Technology, Danvers, MA, USA), anti-rabbit IgG $(\mathrm{H}+\mathrm{L}), \mathrm{F}\left(\mathrm{ab}^{\prime}\right)_{2}$ Fragment (Alexa Fluor ${ }^{\ominus} 488$ Conjugate) (\#4412; Cell Signaling Technology), and DAPI $(0.5 \mu \mathrm{g} / \mathrm{ml}$; Sigma, St. Louis, MO, USA). Protein expression and morphological changes of the nucleus were examined under fluorescence microscopy.

\section{RNA interference}

Per2 small interfering (si) RNA (s16931; Life Technologies) and Bik siRNA (s1990; Life Technologies) were transfected into synovial fibroblasts $\left(3.0 \times 10^{3}\right.$ cells $)$ using Lipofectamine ${ }^{\text {Tu }}$ RNAiMAX (Life Technologies) for 48 h. Noncoding siRNA $(4,390,843$; Life Technologies) was also used as controls. After that, cells were cultured in serum-free DMEM with $10 \mathrm{nM}$ of MTX for $24 \mathrm{~h}$ to measure cell viabilities using the Cell Counting Kit-8. The viabilities were represented relative to those of noncoding siRNA without MTX treatment.

\section{Statistical analyses}

In dynamite-plunger plots, values were expressed as the mean \pm standard error of the mean (SEM). In boxplots, values were expressed with 10th, 25th, 50th (median), 75th, and 90th percentiles, and the single values were superimposed on the boxplots using black symbols.

For statistical analyses, a one-sample Kolmogorov-Smirnov test was used to test the normality, A one-sample $t$ test was used to compare one single control value and others, a paired $t$ test was used to compare differences between two experimental groups, the Tukey test was used to compare differences between more than three experimental groups, and Dunnett's test was used to compare differences between the control and others. All statistical tests were twosided and $p<0.05$ was considered statistically significant.

The statistical analyses were performed by EZR, based on $\mathrm{R}$ and $\mathrm{R}$ commander [32].

\section{Results}

MTX inhibited viabilities of synovial fibroblasts

We first examined the effect of MTX on viabilities of synovial fibroblasts. A lower concentration of MTX $(1,10$ nM) significantly decreased cell viabilities, while cell viability was relatively weak with a higher concentration of MTX (100 nM, $1 \mu \mathrm{M})$ (Fig. 1). Since 10 or $100 \mathrm{nM}$ was the optimum MTX concentration in human sera [33], experiments were subsequently conducted with MTX 10 $\mathrm{nM}$ treatment as an appropriate effective concentration and a concentration of $100 \mathrm{nM}$ as a less-effective control.

\section{MTX accelerated the expression of circadian clock gene Per2}

We next determined the effect of MTX on expressions of circadian clock genes. Under treatment with MTX (10

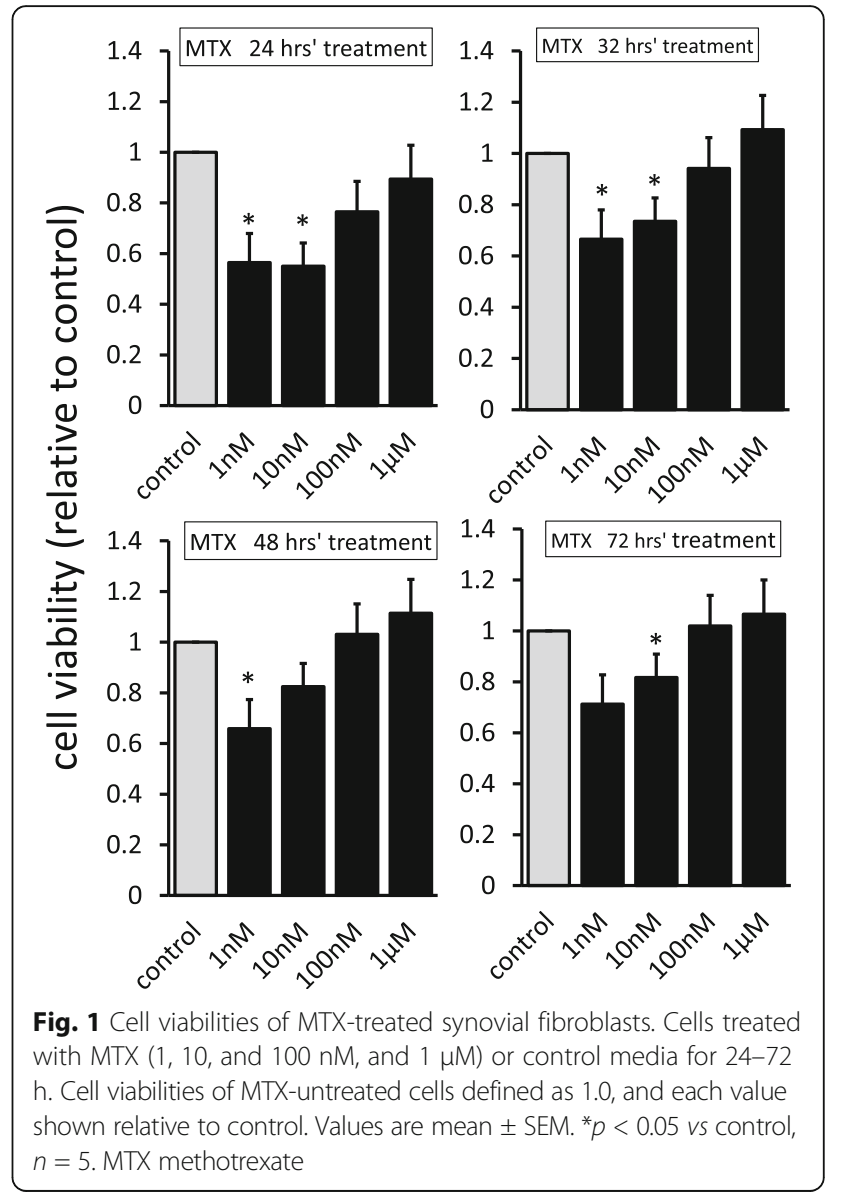

nM for $24 \mathrm{~h}$ ), the expression of Per2 messenger RNA (mRNA) was significantly increased, while expression of Bmal1, Clock, and Cry1 mRNA was not. In contrast, under treatment with MTX (100 nM for $24 \mathrm{~h}$ ), the expression of Per2 did not show any significant differences, while the expression of Clock and Cry1 significantly decreased (Fig. 2a). In accordance with this, the expression of PER2 protein was significantly increased by $10 \mathrm{nM}$ of MTX for 32 h, but not by $100 \mathrm{nM}$ (Fig. 2b, c).

\section{MTX increased the expression of PAR bZIP and Bik}

The circadian transcriptional factor PAR bZIP ( $D b p$, Tef, and $H l f)$ and $E 4 b p 4$ genes regulate Per 2 gene expression by binding to D-box on the promoter region [23-28]. We therefore examined the effect of MTX on the mRNA expression of $D b p$, Tef, $H l f$, and E4bp 4. Expression of $D b p$, $T e f$, and Tef mRNA was significantly increased by $10 \mathrm{nM}$ MTX treatment for $24 \mathrm{~h}$, while E4bp4 mRNA expression was not. However, expression of $D b p$ and E4bp4 significantly decreased with $100 \mathrm{nM}$ of MTX treatment (Fig. 3a).

Next, we examined the mRNA expression of the proapoptotic factor $B i k$, since the PAR bZIP-binding site also exists on the promoter region of Bik [29]. As shown in 
a

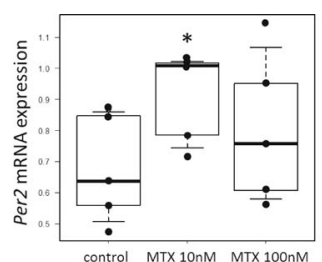

control MTX10nM MTX100nM

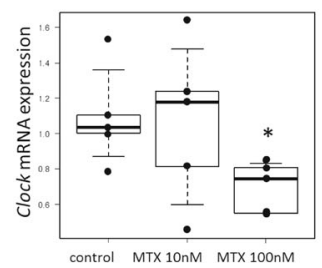

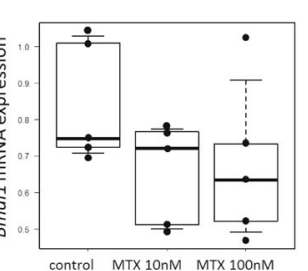

control MTX $10 \mathrm{nM}$ MTX $100 \mathrm{nM}$

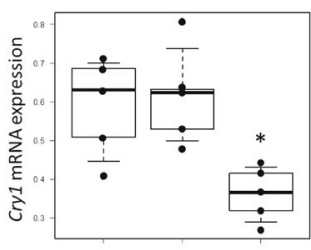

control MTX 10nM MTX 100nM b

MTX (nM)

PER2

Actin
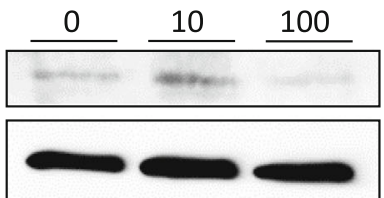

C

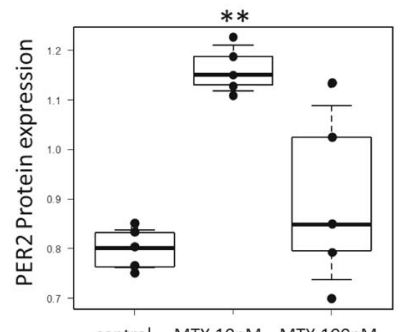

Fig. 2 Effect of MTX on expression of core circadian clock genes in synovial fibroblasts. a Cells treated with MTX (10, $100 \mathrm{nM})$ or control media for $24 \mathrm{~h}$ to measure mRNA expression of Per2, Bmal1, Clock, and Cry1. Values given with 10th, 25th, 50th (median), 75th, and 90th percentiles and single values superimposed on the boxplots using black symbols. ${ }^{*} p<0.05$ vs control, $n=5$. b Cells treated with MTX (10, $\left.100 \mathrm{nM}\right)$ or control media for $32 \mathrm{~h}$ to observe PER2 expression. c Cells treated with MTX $(10,100 \mathrm{nM})$ or control media for $32 \mathrm{~h}$ to measure PER2 expression by ELISA. Values given with 10th, 25th, 50th (median), 75th, and 90th percentile and single values superimposed on the boxplots using black symbols. ${ }^{* *} \mathrm{p}$ $<0.01$ vs control, $n=5$. Bmal1 brain and muscle Arnt-like protein-1, Clock circadian locomotor output cycles kaput, Cry cryptochrome, mRNA messenger RNA, MTX methotrexate, Per period

a

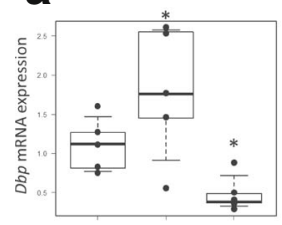
control MTX 10nM MTX 100nM

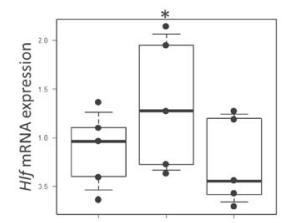

b

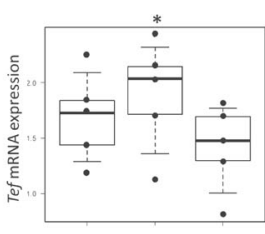

control MTX 10 MM MTX 100nM

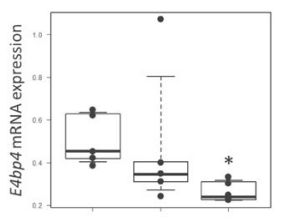

control MTX 10nM MTX $100 \mathrm{nM}$

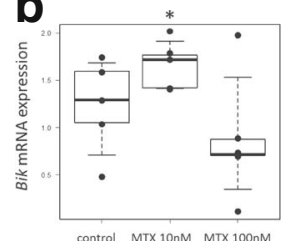

C

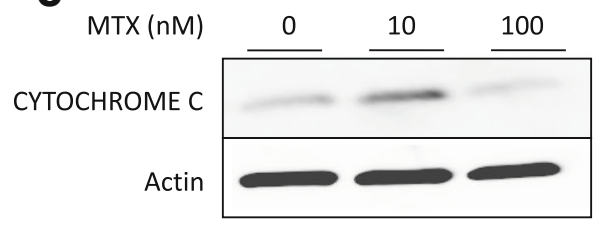

d

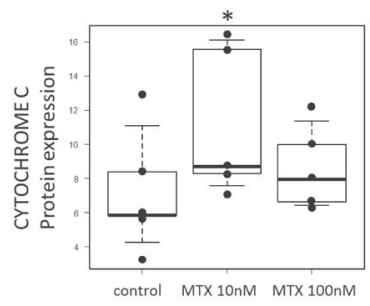

Fig. 3 Effect of MTX on expression of circadian transcriptional factors PAR bZIP and Bik in synovial fibroblasts. a Cells treated with MTX (10, 100 $\mathrm{nM}$ ) or control media for $24 \mathrm{~h}$ to measure expression of PAR bZIP gene mRNA (Dbp, Tef, and HIf) and E4bp4. Values given with 10th, 25th, 50th (median), 75th, and 90th percentiles and single values superimposed on boxplots using black symbols. ${ }^{*} p<0.05$ vs control, $n=5$. $\mathbf{b}$ Cells treated with MTX $(10,100 \mathrm{nM})$ or control media for $24 \mathrm{~h}$ to measure expression of Bik gene mRNA. Values given with 10th, 25th, 50th (median), 75th, and 90th percentiles and single values superimposed on boxplots using black symbols. ${ }^{*} p<0.05$ vs control, $n=5$. c Cells treated with MTX (10, 100 $\mathrm{nM}$ ) or control media for $48 \mathrm{~h}$ to observe CYTOCHROME C expression. $\mathbf{d}$ Cells treated with MTX $(10,100 \mathrm{nM})$ or control media for $48 \mathrm{~h}$ to measure CYTOCHROME C expression by ELISA. Values given with 10th, 25th, 50th (median), 75th, and 90th percentiles and single values superimposed on boxplots using black symbols. ${ }^{*} p<0.05$ vs control, $n=5$. Bik Bcl-2 interacting killer, Dbp D site of the albumin promoter binding protein, E4bp4 E4-binding protein 4, HIf hepatic leukemia factor, mRNA messenger RNA, MTX methotrexate, Tef thyrotroph embryonic factor 
Fig. 3b, the expression of Bik mRNA was significantly increased by $10 \mathrm{nM}$ of MTX treatment for $32 \mathrm{~h}$.

Finally, we observed cytosolic release of CYTOCHROME $\mathrm{C}$ since Bik interacted with BCL-2 family proteins to induce mitochondria-related apoptosis. As a result, expression of CYTOCHROME $\mathrm{C}$ was increased by $10 \mathrm{nM}$ of MTX treatment for 48 h, but not by $100 \mathrm{nM}$ (Fig. 3c, d).

\section{Transcription of Per2 and Bik was enhanced via D-box}

To examine the roles of PAR bZIP in the transcription of Per2 and Bik, we transfected luciferase reporters, constructed with or without D-box, to synovial fibroblasts. With $10 \mathrm{nM}$ of MTX treatment for $24 \mathrm{~h}, \mathrm{D}-\mathrm{box}(+) \operatorname{Per} 2$ promoter activity was significantly increased as compared to those of the control and D-box(-) Per2 promoter. By 100 nM of MTX treatment, D-box(-) Per2 promoter activity was significantly decreased as compared to that of the control. Bik promoter activity was significantly increased after $10 \mathrm{nM}$ of MTX treatment, and was higher than that of D-box(-) Bik promoter (Fig. 4).

\section{PER2, BIK, and CYTOCHROME C were highly expressed in apoptotic cells}

To certify the specific expression of Per2 and Bik on MTX-induced apoptotic synovial fibroblasts, we used fluorescent immunostaining to examine expressions of PER2, BIK, and CYTOCHROME C and, simultaneously, morphological changes of nucleus. As a result, nuclear blebbing, shrinkage, or fragmentation were observed indicating that MTX (10 nM for $24 \mathrm{~h}$ ) could induce cell death. PER2 was overexpressed on apoptotic cells, but not on cells with normal appearance (Fig. 5a). BIK and CYTOCHROME $\mathrm{C}$ were also overexpressed specifically on the apoptotic cells (Fig. 5b).

Per2 and Bik are critical genes for MTX-induced apoptosis To confirm whether PER2 and BIK were responsible for MTX-induced cell death, Per2 and Bik siRNA were transfected into synovial fibroblasts to examine cell viabilities. As shown in Fig. 6a, cytotoxicity of MTX was attenuated by silencing of Per 2 and Bik, independently and synergistically.

When we examined the long-term expression of Per2 and Bik mRNA (Fig. 6b), they gradually increased from $8 \mathrm{~h}$ until 24 or $32 \mathrm{~h}$ after synchronized circadian oscillations by serum shock, consistent with our previous report that the expression of Per2 on synovial fibroblasts was increased after synchronization and peaked at $24 \mathrm{~h}$ [17]. Since these genes were responsible for MTX-induced cell death, synovial fibroblasts were separately treated by $10 \mathrm{nM}$ of MTX at $0-8 \mathrm{~h}$ (the lower Per2/Bik expression period) and at 24-32 $\mathrm{h}$ (the higher Per2/Bik expression period), and viabilities of synovial fibroblasts were again measured. As shown in Fig. 6c, the reduction rate of cell viabilities was
D-box (+); plasmid constructs containing D-box D-box (-); plasmid constructs without D-box
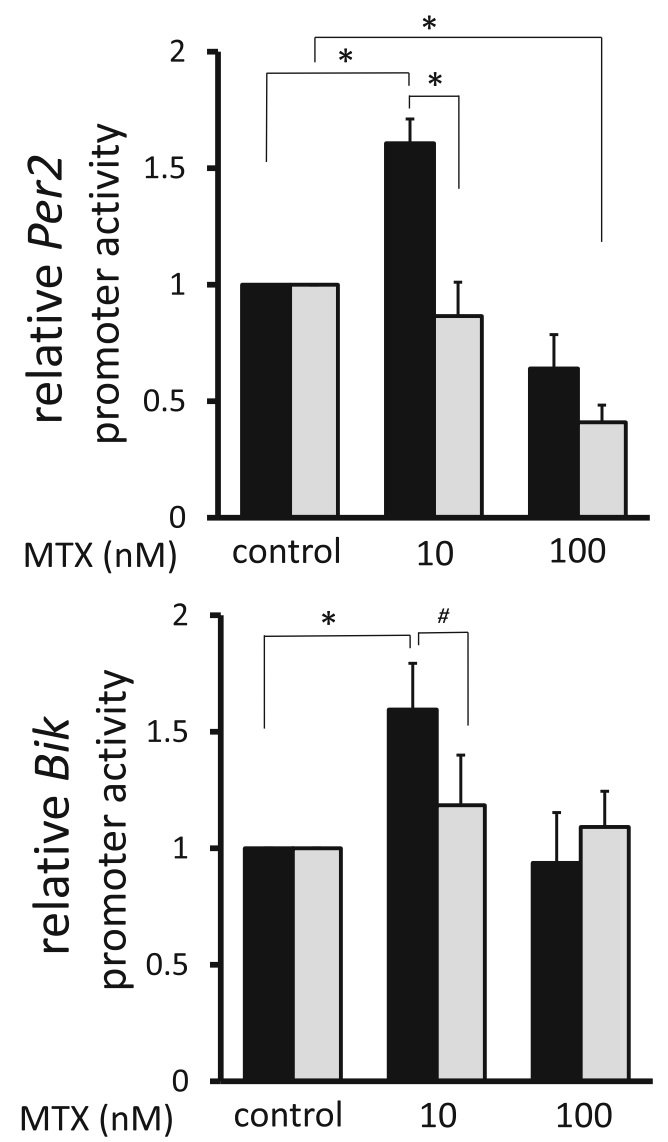

Fig. 4 Promoter activities of Per2 and Bik under MTX treatment. Synovial fibroblasts transfected with vectors containing various Per2 or Bik promoters for $24 \mathrm{~h}$. After treatment with MTX (10, $100 \mathrm{nM})$ or control media for $24 \mathrm{~h}$, luciferase reporter assay was performed. Promoter activities of MTX-untreated cells defined as 1.0, and each value shown relative to control. Values are mean \pm SEM. ${ }^{*} p<0.05, \# p<0.1, n=5$ (Per2), $n=6$ (Bik). Bik BCl-2 interacting killer, MTX methotrexate, Per period

significantly increased by 24-32 h of MTX treatment compared with $0-8 \mathrm{~h}$ of treatment, depending on the expression levels of Per2 and Bik.

\section{Discussion}

We present here a novel pharmacological action of MTX in the viewpoint of circadian clock genes, circadian transcriptional factor PAR bZIP, and proapoptotic molecule Bik. In addition, a crucial mechanism of MTX-induced apoptosis on rheumatoid synovial fibroblasts was further traced.

In this study, the effect of MTX on cell viabilities did not show a concentration-dependent manner, with a wide range of MTX concentrations from $1 \mathrm{nM}$ to $1 \mu \mathrm{M}$. In addition to our result, we found that MTX concentrations lower than 1 $\mathrm{nM}$ did not decrease cell viability (see Additional file 4). MTX is transferred almost equally to synovial fluid and sera, 

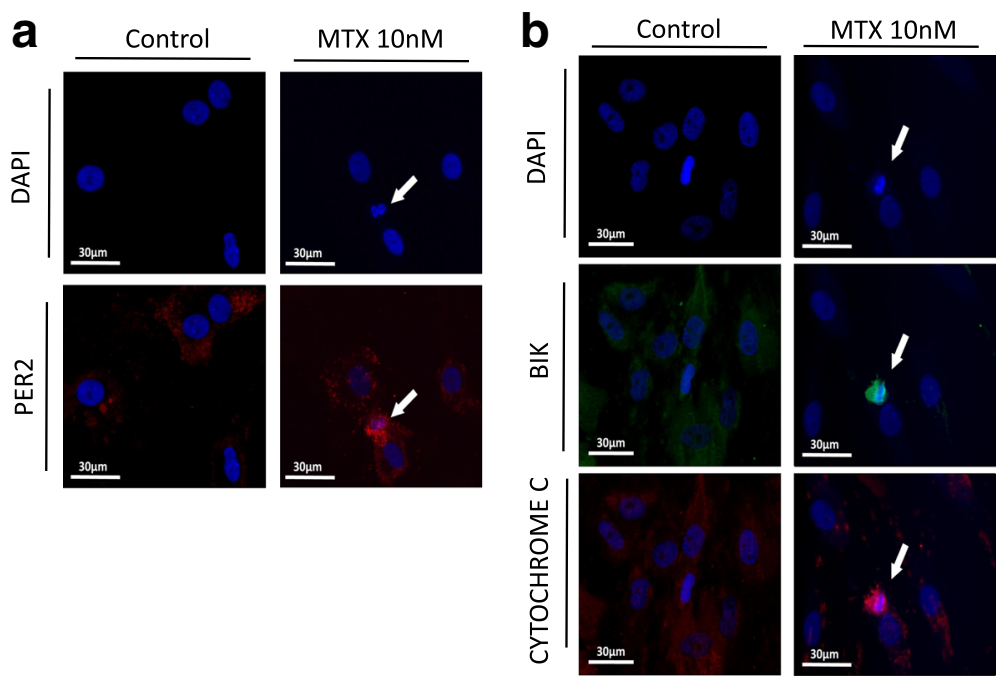

Fig. 5 PER2, BIK, and CYTOCHROME C expression and morphological changes of the nucleus. a Cells stained with DAPI and anti-PER2 Ab after treatment with MTX $(10,100 \mathrm{nM})$ or control media for $24 \mathrm{~h}$. Arrowheads indicate apoptotic cells. b Cells stained with DAPI, anti-BIK Ab, and antiCYTOCHROME C Ab after treatment with MTX (10, $100 \mathrm{nM})$ or control media for $24 \mathrm{~h}$. Arrowheads indicate apoptotic cells. Bik Bcl-2 interacting killer, DAPI 4',6-diamidino-2-phenylindole, MTX methotrexate, Per period

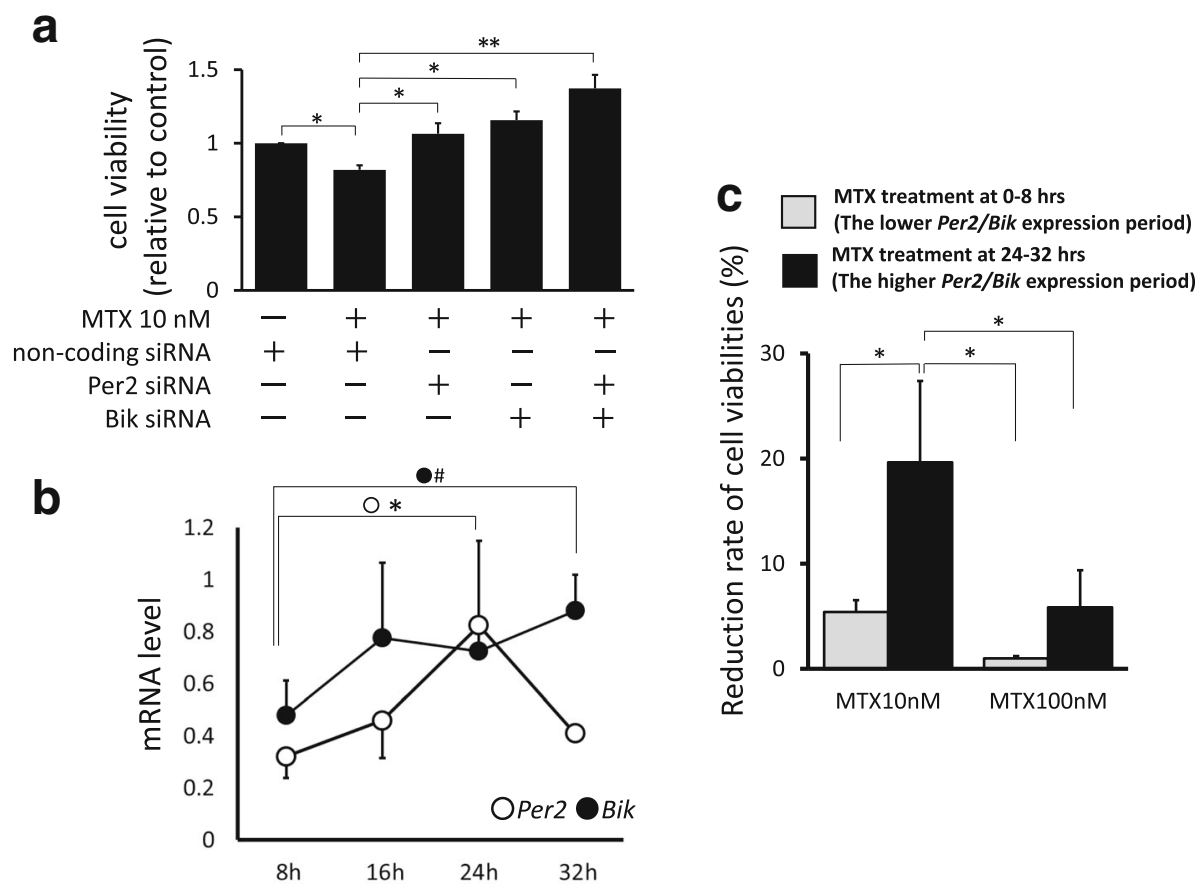

Fig. 6 Cell viabilities after RNA interfering of Per2 and Bik, and long-term expression of Per2 and Bik mRNA under MTX treatment. a After transfection with Per2 or Bik siRNA, cells treated with MTX $(10,100 \mathrm{nM})$ or control media for $24 \mathrm{~h}$ to measure cell viabilities. Cell viabilities of control (MTX-untreated cells) defined as 1.0, and each value shown relative to control. Values are mean \pm SEM. ${ }^{*} p<0.05,{ }^{* *} p<0.01, n=5$. b Long-term expression of Per2 and Bik. After $8,16,24$, and $32 \mathrm{~h}$ of culture in serum-free media, mRNA was extracted from synovial fibroblasts to measure expressions of Per2 and Bik. Values are mean \pm SEM. ${ }^{*} p<0.05, \# p<0.1, n=5$. c Reduction rate of cell viabilities under time-dependent MTX treatments. Viabilities of synovial fibroblasts after treatment with $10 \mathrm{nM}$ of MTX at 0-8 h (lower Per2/Bik expression period) or 24-32 $\mathrm{h}$ (higher Per2/Bik expression period) measured, respectively. Cell viabilities of MTX-untreated cells defined as $100 \%$, and values are mean $\pm \mathrm{SEM}$. ${ }^{*} p<0.05, n=5$. Bik Bcl-2 interacting killer, mRNA messenger RNA, MTX methotrexate, Per period 
and the concentration of MTX in human sera can reach $200 \mathrm{nM}$ at the peak and immediately decreases to less than $10 \mathrm{nM}$ [33], although pharmacological effects on cytotoxicity or cellular viability may not necessarily increase in a concentration-dependent manner. As reported previously, viabilities of human lymphoblastic leukemia cells and epithelial cells of rat decreased in a concentration-dependent manner at low MTX concentrations, but did not show a significant decrease at high MTX concentrations [34, 35]. Moreover, MTX did not affect viability in a concentration-dependent manner on $\mathrm{T}$ cells and RA synovial fibroblasts, in contrast to those of dose dependency observed in osteoarthritis synovial fibroblasts $[6,36]$. Thus, further studies are required for the action of MTX correlated with drug dosage or cell types.

Since MTX concentrations below $100 \mathrm{nM}$ were conceivable in sera of RA patients, we next focused on the effect of MTX on circadian clock genes and circadian transcriptional factor PAR bZIP genes and their relations to mitochondria-related apoptosis of synovial fibroblasts.

Since circadian clock genes were reported to be closely related to the pathogenesis of arthritis $[16,37]$ and excessive expression of Per2 could induce apoptosis [38], we examined the effect of MTX on expression of Per2, Bmal1, Clock, and Cry1 that were regarded as "core" clock genes [20-22]. We examined mRNA expression of circadian clock genes over time, and found that the controls and 10/100 nM of MTX showed almost the same expression rhythms, and MTX influenced their expression levels (see Additional file 5).

As described, both Per2 and Bik genes have D-box in their promoter regions, and PAR bZIP proteins regulate the expression of these genes by binding to D-box [24, 39]. Indeed, promoter activities of Per2 and Bik were upregulated by $10 \mathrm{nM}$ of MTX when the D-box sequence exists and were cancelled without D-box. Moreover, both PER2 and BIK were highly expressed in MTX-induced apoptotic cells, while inhibitions of Per2 and Bik synergistically attenuated the effect of MTX on cellular viabilities. As it has been reported that PAR bZIP and Bik mediate oxidative stress-induced apoptosis in fibroblasts [39], we consider Per2 and Bik as essential factors for MTX-dependent synovial cell death and propose here that two independent pathways can mediate these death signals: the PAR bZIP-Per2 transcriptional pathway and the PAR bZIP-Bik transcriptional pathway (see Additional file 6). However, as shown in Fig. 2a, downregulation of Clock and Cry1 appeared to be less effective on cell viabilities after treatment with $100 \mathrm{nM}$ of MTX. Further in-vivo study should be required for clinical application by investigating the cross-talk of clock genes.

Last, because of the similarity of their promoter region containing D-box, we supposed Bik might show oscillation as has been reported for Per2 [17, 31]. For the further understanding of circadian manifestation in rheumatoid arthritis, we showed that the expression of $B i k$, as well as Per2, was gradually increased from $8 \mathrm{~h}$ until 24 or $32 \mathrm{~h}$, and MTX was significantly effective in situations when Per 2 and Bik were highly expressed. It has been reported that administration of MTX at bedtime, as an optimal dosing time associated with the oscillation of TNF- $\alpha$ production, could reduce the disease activities of patients with RA [40, 41]. Thus, we considered that expression levels of Per 2 and Bik could also be a critical biomarker for chronotherapy of MTX not only for RA, but also for other diseases such as acute lymphocytic leukemia, nonHodgkin's lymphoma, osteosarcoma, and breast cancer, in accordance with a previous report that circadian clock genes could be a biomarker for chronotherapy [42].

\section{Conclusions}

We propose here that MTX induces apoptosis in synovial fibroblasts through the binding of PAR bZIP to D-box of two different genes, Per2 and Bik, and these dual pathways work independently but synergistically. In consequence, MTX acts as a modulator of circadian environments of synovial fibroblasts in relation to biological clock genes and circadian transcriptional factors.

\section{Additional files}

Additional file 1: The interactions of circadian clock genes and its relative factors. BMAL/CLOCK and PER/CRY create the circadian rhythm via E-box, and DBP, TEF, HLF, E4BP4 via D-box. BMAL and CLOCK heterodimerize and bind to E-box elements on promoter regions of Per and Cry genes to induce their transcription. Thereafter, PER and CRY proteins heterodimerize to inhibit activities of their own and other E-box regulated promoters. (PDF $214 \mathrm{~kb}$ )

Additional file 2: Detailed information of patients with RA enrolled in this study. Joint samples obtained from 10 different patients to establish primary cultured synovial fibroblast cell lines. Age, sex, disease duration, CRP, DAS28-ESR, and treatment with MTX, PSL, and other DMARDs shown in the table. (PDF $252 \mathrm{~kb}$ )

Additional file 3: Plasmid constructs of Per2/Bik promoter. D-box(+), plasmid constructs containing D-box. D-box(-), plasmid constructs without D-box. D-box motifs of Per2 promoter were mutated from 5'-TTATGTAA-3' to 5'CGCCAGGC-3' (-372 to -365 ), and 5'-TTACGTAA-3' to 5'-CAGCGTAA-3' (-47 to $-40)$. Human Bik promoter containing D-box $(-780$ to +176$)$ and human Bik promoter without D-box (-260 to +323) constructed. (PDF 215 kb)

Additional file 4: Cell viability of MTX-treated fibroblasts. Cell viability of RA synovial fibroblasts measured by WST- 8 assay after $24 \mathrm{~h}$ of stimulation of MTX (1 pM to $1 \mu \mathrm{M})$. MTX (1 and $10 \mathrm{nM}$ ) significantly decreased cell viability as shown in Fig. 1, while 1-100 pM of MTX did not. (PDF 274 kb)

Additional file 5: The mRNA expression of circadian clock genes over time. mRNA expression of circadian clock genes measured at $-4 \mathrm{~h}$ (before synchronization), $0 \mathrm{~h}$ (just before MTX stimulation), $24 \mathrm{~h}, 32 \mathrm{~h}$, and $48 \mathrm{~h}$. Controls and 10/100 nM of MTX showed almost the same expression rhythms, and MTX influenced their expression levels. (PDF 264 kb)

Additional file 6: Two different transcriptional pathways by which MTX induces apoptosis to synovial fibroblasts: PAR bZIP_Per2 transcriptional pathway and PAR bZIP-Bik transcriptional pathway. We propose MTX induces apoptosis in synovial cells through activated binding of PAR bZIP to D-box in two different genes, Per2 and Bik, and these dual pathways work independently but synergistically. (PDF 206 kb) 


\section{Abbreviations}

Ab: Antibody; Bik: Bcl-2 interacting killer; Bmal1: Brain and muscle Arnt-like protein-1; Clock: Circadian locomotor output cycles kaput; Cry: Cryptochrome; Dbp: D site of the albumin promoter binding protein: DMEM: Dulbecco's modified Eagle's medium; E4bp4: E4-binding protein 4; FBS: Fetal bovine serum; HIf: Hepatic leukemia factor; Ig: Immunoglobulin; mRNA: Messenger RNA; MTX: Methotrexate; PAR bZIP: Proline and acidic amino acid-rich basic leucine zipper; PCR: Polymerase chain reaction; Per: Period; PVDF: Polyvinylidene difluoride; RA: Rheumatoid arthritis; SDSPAGE: Sodium dodecyl sulfate polyacrylamide gel electrophoresis; SEM: Standard error of the mean; siRNA: Small interfering RNA; Tbp: TATA box binding protein; Tef: Thyrotroph embryonic factor; TNF: Tumor necrosis factor; WST-8: 2-(2-Methoxy-4-nitrophenyl)-3-(4-nitrophenyl)-5-(2,4disulfophenyl)-2H-tetrazolium

\section{Acknowledgements}

Not applicable.

\section{Funding}

The authors declare that they have no funding.

\section{Availability of data and materials}

The datasets generated during and/or analyzed during the current study are available from the corresponding author on reasonable request.

\section{Authors' contributions}

KS performed and analyzed most of the experiments, and wrote the manuscript. KY, TU, and KK provided technical support for the experiments. $\mathrm{AN}, \mathrm{NH}$, and $\mathrm{KU}$ maintained synovial fibroblasts and exchanged useful arguments on this manuscript. TH, YK, NS, and NN collected synovial samples. YS supervised the project. AH conceived the idea for the project, supervised the experiments, and wrote the manuscript. All authors read and approved the final manuscript.

\section{Ethics approval and consent to participate}

This study has been approved by the ethics committee of Kobe University Graduate School of Health Sciences (\#579-1) and Kobe Kaisei Hospital (\#0072), in accordance with the Declaration of Helsinki. Written informed consent was obtained from each patient before study enrolment.

\section{Consent for publication}

Not applicable.

\section{Competing interests}

The authors declare that they have no competing interests.

\section{Publisher's Note}

Springer Nature remains neutral with regard to jurisdictional claims in published maps and institutional affiliations.

\section{Author details \\ 'Department of Biophysics, Kobe University Graduate School of Health Sciences, Tomogaoka 7-10-2, Suma-ku, Kobe 654-0142, Japan. ²Division of Rehabilitation Medicine, Kobe University Graduate School of Medicine, Kobe 650-0017, Japan. ${ }^{3}$ Department of Rheumatology, Kobe Kaisei Hospital, Kobe 657-0068, Japan. ${ }^{4}$ Department of Orthopedic Surgery, Kobe Kaisei Hospital, Kobe 657-0068, Japan. ${ }^{5}$ Department of Rheumatology, Hyogo Prefectural Kakogawa Medical Center, Kakogawa 675-0003, Japan. \\ Received: 25 September 2017 Accepted: 25 February 2018 Published online: 22 March 2018}

\section{References}

1. Jolivet J, Cowan KH, Curt GA, Clendeninn NJ, Chabner BA. The pharmacology and clinical use of methotrexate. N Engl J Med. 1983;309:1094-104.

2. Bleyer WA. The clinical pharmacology of methotrexate: new applications of an old drug. Cancer. 1978;41:36-51.

3. Cronstein BN. Low-dose methotrexate: a mainstay in the treatment of rheumatoid arthritis. Pharmacol Rev. 2005;57:163-72.

4. Cutolo M, Sulli A, Pizzorni C, Seriolo B, Straub RH. Anti-inflammatory mechanisms of methotrexate in rheumatoid arthritis. Ann Rheum Dis. 2001;60:729-35.
5. Nakazawa F, Matsuno H, Yudoh K, Katayama R, Sawai T, Uzuki M, et al Methotrexate inhibits rheumatoid synovitis by inducing apoptosis. J Rheumatol. 2001;28:1800-8.

6. Xu K, Cai YS, Lu SM, Li XL, Liu L, Li Z, et al. Autophagy induction contributes to the resistance to methotrexate treatment in rheumatoid arthritis fibroblast-like synovial cells through high mobility group box chromosomal protein 1. Arthritis Res Ther. 2015;17:374.

7. Lee SY, Park SH, Lee SW, Lee SH, Son MK, Choi YH, et al. Synoviocyte apoptosis may differentiate responder and non-responder patients to methotrexate treatment in rheumatoid arthritis. Arch Pharm Res. 2014;37:1286-94.

8. Spurlock CF 3rd, Gass HM 4th, Bryant CJ, Wells BC, Olsen NJ, Aune TM. Methotrexate-mediated inhibition of nuclear factor $\mathrm{KB}$ activation by distinct pathways in T cells and fibroblast-like synoviocytes. Rheumatology. 2014;54:178-87.

9. Olsen NJ, Stein CM. New drugs for rheumatoid arthritis. N Engl J Med. 2004; 350:2167-79.

10. Arnett FC, Edworthy SM, Bloch DA, McShane DJ, Fries JF, Cooper NS, et al. The American Rheumatism Association 1987 revised criteria for the classification of rheumatoid arthritis. Arthritis Rheum. 1988;31:315-24.

11. Cutolo M, Straub RH, Buttgereit F. Circadian rhythms of nocturnal hormones in rheumatoid arthritis: translation from bench to bedside. Ann Rheum Dis. 2008;67:905-8.

12. Danis VA, Franic GM, Rathjen DA, Laurent RM, Brooks PM. Circulating cytokine levels in patients with rheumatoid arthritis: results of a double blind trial with sulphasalazine. Ann Rheum Dis. 1992;51:946-50.

13. Dasgupta B, Corkill M, Kirkham B, Gibson T, Panayi G. Serial estimation of interleukin 6 as a measure of systemic disease in rheumatoid arthritis. J Rheumatol. 1992;19:22-5.

14. Choy EH, Panayi GS. Cytokine pathways and joint inflammation in rheumatoid arthritis. N Engl J Med. 2001;344:907-16.

15. Straub RH, Cutolo M. Circadian rhythms in rheumatoid arthritis: implications for pathophysiology and therapeutic management. Arthritis Rheum. 2007; 56:399-408

16. Hashiramoto A, Yamane T, Tsumiyama K, Yoshida K, Komai K, Yamada H, et al. Mammalian clock gene Cryptochrome regulates arthritis via proinflammatory cytokine TNF-a. J Immunol. 2010;184:1560-5.

17. Yoshida K, Hashiramoto A, Okano T, Yamane T, Shibanuma N, Shiozawa S. TNF-a modulates expression of the circadian clock gene Per2 in rheumatoid synovial cells. Scand J Rheumatol. 2013:42:276-80.

18. Haas S, Straub RH. Disruption of rhythms of molecular clocks in primary synovial fibroblasts of patients with osteoarthritis and rheumatoid arthritis, role of IL-1ß/TNF. Arthritis Res Ther. 2012;14:R122.

19. Cutolo M, Villaggio B, Otsa K, Aakre O, Sulli A, Seriolo B. Altered circadian rhythms in rheumatoid arthritis patients play a role in the disease's symptoms. Autoimmun Rev. 2005;4:497-502.

20. Gibbs JE, Ray DW. The role of the circadian clock in rheumatoid arthritis. Arthritis Res Ther. 2013;15:205.

21. Cuninkova L, Brown SA. Peripheral circadian oscillators: interesting mechanisms and powerful tools. Ann N Y Acad Sci. 2008;1129:358-70.

22. Sato TK, Yamada RG, Ukai H, Baggs JE, Miraglia LJ, Kobayashi TJ, et al. Feedback repression is required for mammalian circadian clock function. Nat Genet. 2006;38:312-9.

23. Falvey $E$, Marcacci $L$, Schibler $U$. DNA-binding specificity of PAR and C/ EBP leucine zipper proteins: a single amino acid substitution in the C/ EBP DNA-binding domain confers PAR-like specificity to C/EBP. Biol Chem. 1996:377:797-809.

24. Li S, Hunger SP. The DBP transcriptional activation domain is highly homologous to that of HLF and TEF and is not responsible for the tissue type-specific transcriptional activity of DBP. Gene. 2001;263:239-45.

25. Cowell IG, Skinner A, Hurst HC. Transcriptional repression by a novel member of the bZIP family of transcription factors. Mol Cell Biol. 1992;12:3070-7.

26. Mitsui S, Yamaguchi S, Matsuo T, Ishida Y, Okamura H. Antagonistic role of E4BP4 and PAR proteins in the circadian oscillatory mechanism. Genes Dev. 2001;15:995-1006

27. Yamajuku D, Shibata Y, Kitazawa M, Katakura T, Urata H, Kojima T, et al. Cellular DBP and E4BP4 proteins are critical for determining the period length of the circadian oscillator. FEBS Lett. 2011;585:2217-22.

28. Ohno T, Onishi Y, Ishida N. A novel E4BP4 element drives circadian expression of mPeriod2. Nucleic Acids Res. 2007:35:648-55.

29. Rashmi R, Pillai SG, Vijayalingam S, Ryerse J, Chinnadurai G. BH3-only protein BIK induces caspase-independent cell death with autophagic features in Bcl-2 null cells. Oncogene. 2008;27:1366-75. 
30. Boyd JM, Gallo GJ, Elangovan B, Houghton AB, Malstrom S, Avery BJ, et al. Bik, a novel death-inducing protein shares a distinct sequence motif with $\mathrm{BCl}-2$ family proteins and interacts with viral and cellular survival-promoting proteins. Oncogene. 1995:11:1921-8.

31. Balsalobre A, Damiola F, Schibler U. A serum shock induces circadian gene expression in mammalian tissue culture cells. Cell. 1998:93:929-37.

32. Kanda Y. Investigation of the freely available easy-to-use software 'EZR' for medical statistics. Bone Marrow Transplant. 2013;48(3):452-8.

33. Shiozawa K, Tanaka Y, Yoshihara R, Imura S, Murata M, Yamane T, et al, Serum levels and pharmacodynamics of methotrexate and its metabolite 7hydroxy methotrexate in Japanese patients with rheumatoid arthritis treated with 2-mg capsule of methotrexate three times per week. Mod Rheumatol. 2005;15:405-9.

34. Haber M, Madafiglio J, Norris MD. Methotrexate cytotoxicity determination using the MTT assay following enzymatic depletion of thymidine and hypoxanthine. J Cancer Res Clin Oncol. 1993;119(6):315-7.

35. Horie T, Li T, Ito K, Sumi S, Fuwa T. Aged garlic extract protects against methotrexate-induced apoptotic cell injury of IEC-6 cells. J Nutr. 2006;136(3 Suppl):861S-3S.

36. Genestier L, Paillot R, Fournel S, Ferraro C, Miossec P, Revillard JP. Immunosuppressive properties of methotrexate: apoptosis and clonal deletion of activated peripheral T cells. J Clin Invest. 1998;102(2):322-8.

37. Hand LE, Hopwood TW, Dickson SH, Walker AL, Loudon AS, Ray DW, et al. The circadian clock regulates inflammatory arthritis. FASEB J. 2016;30(11): 3759-70.

38. Hua $\mathrm{H}$, Wang $Y$, Wan $\mathrm{C}$, Liu Y, Zhu B, Yang $\mathrm{C}$, et al. Circadian gene mPer2 overexpression induces cancer cell apoptosis. Cancer Sci. 2006;97:589-96.

39. Ritchie A, Gutierrez O, Fernandez-Luna JL. PAR bZIP-bik is a novel transcriptional pathway that mediates oxidative stress-induced apoptosis in fibroblasts. Cell Death Differ. 2009;16:838-46.

40. To H, Irie S, Tomonari M, Watanabe $\mathrm{Y}$, Kitahara T, Sasaki H. Therapeutic index of methotrexate depends on circadian cycling of tumour necrosis factor-alpha in collagen-induced arthritic rats and mice. J Pharm Pharmacol. 2009:61:1333-8.

41. To H, Yoshimatsu H, Tomonari M, Ida H, Tsurumoto T, Tsuji Y, et al. Methotrexate chronotherapy is effective against rheumatoid arthritis. Chronobiol Int. 2011;28:267-74.

42. Tang $\mathrm{Q}$, Cheng B, Xie M, Chen Y, Zhao J, Zhou X, et al. Circadian clock gene Bmal1 inhibits tumorigenesis and increases paclitaxel sensitivity in tongue squamous cell carcinoma. Cancer Res. 2017:77:532-44.

\section{Submit your next manuscript to BioMed Central and we will help you at every step:}

- We accept pre-submission inquiries

- Our selector tool helps you to find the most relevant journal

- We provide round the clock customer support

- Convenient online submission

- Thorough peer review

- Inclusion in PubMed and all major indexing services

- Maximum visibility for your research

Submit your manuscript at www biomedcentral.com/submit

) Biomed Central 